\title{
Análise temporal da exposição ao mercúrio na população ribeirinha da Amazônia: revisão integrativa
}

\author{
Temporal analysis of exposure to Mercury in the ribeirinha population of Amazonia: \\ integrative review
}

Análisis temporal de la exposición al mercúrio em la población ribeirinha de la Amazonía: revisión integrativa

Bárbara Leticia Corrêa Gomes ${ }^{1 *}$, Adriana Maria Pantoja Malato ${ }^{1}$, Isadora do Nascimento Ribeiro1, Catarina Cristina Fraga da Silva ${ }^{1}$, Estefane Valente da Silva ${ }^{1}$, Davi Silva Santana ${ }^{1}$, Maria Eduarda Libório Martins ${ }^{1}$, Maely Cristine Lima Lourinho², Rafael Carnon dos Santos ${ }^{2}$, Evanildo Lopes Monteiro'.

\section{RESUMO}

Objetivo: Analisar as produções literárias que relacionam a exposição e ingestão de mercúrio pela população ribeirinha na Amazônia e abordar os principais aspectos do cuidado de enfermagem, bem como seus impactos. Métodos: O estudo está pautado na revisão bibliográfica de artigos publicados no período de 2013 a 2021, a coleta de dados ocorreu pela busca de artigos científicos nas bases: Sistema Online de Busca e Análise de Literatura Médica (MEDLINE), Literatura Latino-Americana e do Caribe em Ciências da Saúde (LILACS) e Scientific Eletronic Library Online (Livraria Científica Eletrônico Online (SciELO). Resultados: No total, 8 artigos, sendo disponíveis (1) na MEDLINE, (2) LILACS, (5) SciELO, evidenciaram uma importante relação entre a ingestão de pescados e o índice de mercúrio no organismo humano. Tal relação ocorre de maneira proporcional e acumulativa devido ao sentido na cadeia alimentar. Ademais, foi despertado o alerta sobre a contaminação do ecossistema e, consequentemente, dos seres humanos por metais pesados. Considerações finais: De modo geral, ressalta-se a importância do monitoramento dos níveis de exposição dos ribeirinhos ao metal, assim como observa-se a relevância da continuação de estudos sobre o assunto e da participação da enfermagem para que as estratégias de prevenção e controle sejam melhoradas.

Palavras-chave: Intoxicação por mercúrio, Intoxicação do sistema nervoso por mercúrio, Mercúrio.

\begin{abstract}
Objective: To analyze the literary productions that relate exposure and ingestion of mercury by the riverside population in the Amazon and to address the main aspects of nursing care, as well as their impacts. Methods: The study is based on the bibliographic review of articles published from 2013 to 2021, the data collection occurred through the search for scientific articles in the bases: Online System for Search and Analysis of Medical Literature (MEDLINE), Latin American Literature and of the Caribbean in Health Sciences (LILACS) and Scientific Eletronic Library Online (SciELO). Results: In total, 8 articles, being available (1) on MEDLINE, (2) LILACS, (5) SciELO, evidenced an important relationship between the intake of fish and the mercury index in the human body. This relationship occurs in a proportional and cumulative manner due to the meaning in the food chain. by heavy metals. Final considerations: In general, the importance of monitoring the levels of exposure of riverside dwellers to metal is emphasized, as well as the relevance of continuation. studies on the subject and the participation of nursing so that prevention and control strategies are improved.
\end{abstract}

Key words: Mercury poisoning, Mercury nervous system poisoning, Mercury.

\section{RESUMEN}

Objetivo: Analizar las producciones literarias que relacionan la exposición e ingestión de mercurio por la población ribereña de la Amazonía y abordar los principales aspectos del cuidado de enfermería, así como

1 Universidade Federal do Pará (UFPA), Belém - PA. *E-mail: barbaraltc4gomes@gmail.com

${ }^{2}$ Fibra Centro Universitário, Belém - PA.

SUBMETIDO EM: 4/2021

ACEITO EM: 4/2021

PUBLICADO EM: 4/2021 
sus impactos. Métodos: El estudio se basa en la revisión bibliográfica de artículos publicados de 2013 a 2021 , la recolección de datos se dio a través de la búsqueda de artículos científicos en las bases: Sistema Online de Búsqueda y Análisis de Literatura Médica (MEDLINE), Literatura Latinoamericana y de Caribbean in Health Sciences (LILACS) y Scientific Eletronic Library Online (Librería Científica Electrónica Online (SciELO). Resultados: En total, 8 artículos, estando disponibles (1) en MEDLINE, (2) LILACS, (5) SciELO, evidenciaron una relación importante entre la ingesta de pescado y el índice de mercurio en el cuerpo humano. Esta relación se da de manera proporcional y acumulativa debido al significado en la cadena alimentaria. por los metales pesados. Consideraciones finales: En general, la importancia de monitorear los niveles de exposición de los habitantes de las riberas al metal es enfatizado, así como la relevancia de la continuación. estudios sobre el tema y la participación de la enfermería para mejorar las estrategias de prevención y control.

Palabras clave: Envenenamiento por mercurio, Envenenamiento por mercurio del sistema nervioso, Mercurio.

\section{INTRODUÇÃO}

Neste artigo, parte-se da concepção que as comunidades são ocupadas por uma diversidade de grupos étnicos e populações tradicionais que foram construídos historicamente. Desse modo, as relações de trabalho, educação, religião, hábitos alimentares e todo estilo de vida são diferentes para cada população; dentre esses grupos que possuem suas próprias singularidades, estão os ribeirinhos, povos que moram nas proximidades dos rios e residem em palafitas. Estes sobrevivem dos afazeres da caça, da pesca, do plantio, da colheita e de atividades de cunho extremamente braçal, por meio da adoção e adaptação de saberes e técnicas de acordo com suas necessidades e recursos naturais disponíveis (LIRA TM e CHAVES MPSR, 2015).

Entre as décadas de 70 e 80, ocorreu a corrida do ouro na Amazônia e no processo de extrativismo do ouro utilizou-se de maneira indiscriminada o mercúrio, o qual, nessa região do país, ainda está presente em grande concentração nos solos e rios, sendo necessário analisar a contaminação ambiental provocada nos seres humanos, ocasionada por esse metal. Pontua-se que o contágio ocorre na dieta alimentar pelo consumo de alimentos contaminados e afeta a corrente sanguínea, ocasionando problemas no Sistema Nervoso Central (SNC) (SOUZA JR e BARBOSA AC, 2000).

A contaminação, principalmente, do ambiente aquático pelo mercúrio acarreta a sua bioacumulação ao longo da cadeia alimentar neste habitat. Nesse âmbito, a principal via de exposição ao referido metal pesado entre a comunidade especificada é por intermédio da ingestão de alimentos contaminados, mais precisamente os peixes, alimento este considerado um dos principais na dieta dessas populações. Nesse sentido, observase a relação direta entre elevados índices de mercúrio no corpo e alto consumo de pescado. Logo, por possuir o pescado como principal fonte proteica, a comunidade ribeirinha encontra-se extremamente exposta à bioacumulação do mercúrio (COSTA JÚNIOR JMF, et al., 2018).

Os níveis tóxicos encontrados no mercúrio atingem principalmente o sistema nervoso, podendo provocar disfunções musculares e nervosas, nas quais os danos podem acarretar consequências irreversíveis ou mesmo fatais para a saúde do indivíduo. O composto de metilmercúrio $(\mathrm{MeHg})$, que é a forma orgânica do mercúrio encontrada no pescado, quando gera uma exposição aguda nos seres humanos pode ocasionar: debilidade, fadiga, perda de peso, taquicardia, tonturas, surdez, constrição do campo visual, coma, além de outros danos ao sistema nervoso, existindo ainda a possibilidade de óbito. O MeHg também pode provocar intoxicação crônica, sendo caracterizada por distúrbio da sensibilidade nas extremidades, ansiedade, depressão, insônia, podendo aumentar o risco para doenças cardiovasculares (CARTA P, et al., 2003).

No que concerne a geolocalização, a população ribeirinha encontra-se isolada dos serviços de saúde e devido à distância os rios são a principal via de contato com esses serviços, para diminuir os fatores que predispõem essas populações a maior risco de adoecimento, devido à marginalização. Deste modo, faz-se necessário a promoção da saúde, com o intuito de educar a comunidade ribeirinha em virtude do pouco acesso à assistência médica, a fim de melhorar as condições de saúde dessa população (FRANCO EC, et al., 2015). Ademais, a Política Nacional de Saúde Integral das Populações do Campo e da Floresta (PNSIPCF) 
tem por objetivo garantir o direito e o acesso à saúde por meio do Sistema Único de Saúde (SUS) para melhorar a qualidade de vida e promover o bem-estar desta comunidade (BRASIL, 2013).

Logo, diante dos aspectos significativos supracitados, o objetivo deste artigo é analisar de forma analítica as produções literárias que relacionam a ingestão de mercúrio através da alimentação pela população ribeirinha na Amazônia.

\section{MÉTODOS}

Trata-se de um estudo descritivo do tipo Revisão Integrativa da Literatura (RIL), de natureza qualitativa, realizado a partir de pesquisas da temática em artigos científicos publicados entre 2013 e 2021, visto que a temática carece de publicações científicas na área da saúde. A coleta de dados ocorreu nas bases de dados: Sistema Online de Busca e Análise de Literatura Médica (MEDLINE), Literatura Latino-Americana e do Caribe em Ciências da Saúde (LILACS) e Scientific Eletronic Library Online (SciELO).

Utilizou-se na pesquisa como critérios de inclusão artigos gratuitos, disponíveis em texto completo, em língua portuguesa e inglesa. Os critérios de exclusão incluem artigos considerados de publicação de literatura cinza, editoriais, cartas ao editor, artigos incompletos e estudos que não abordam temática relevante ao objetivo do estudo e nem se encaixam nos critérios de inclusão.

\section{RESULTADOS}

A pesquisa embasou-se na seleção de 8 artigos que estavam de acordo com os critérios estabelecidos nos métodos e dentro do objetivo proposto, esses estavam disponíveis: (1) MEDLINE, (2) LILACS e (5) SciELO. Esses foram organizados em categoria e subcategorias, conforme a similaridade dos assuntos abordados e para melhor exemplificá-los foram apresentados na Figura 1.

Figura 1 - Fluxograma de protocolo realizado na pesquisa.

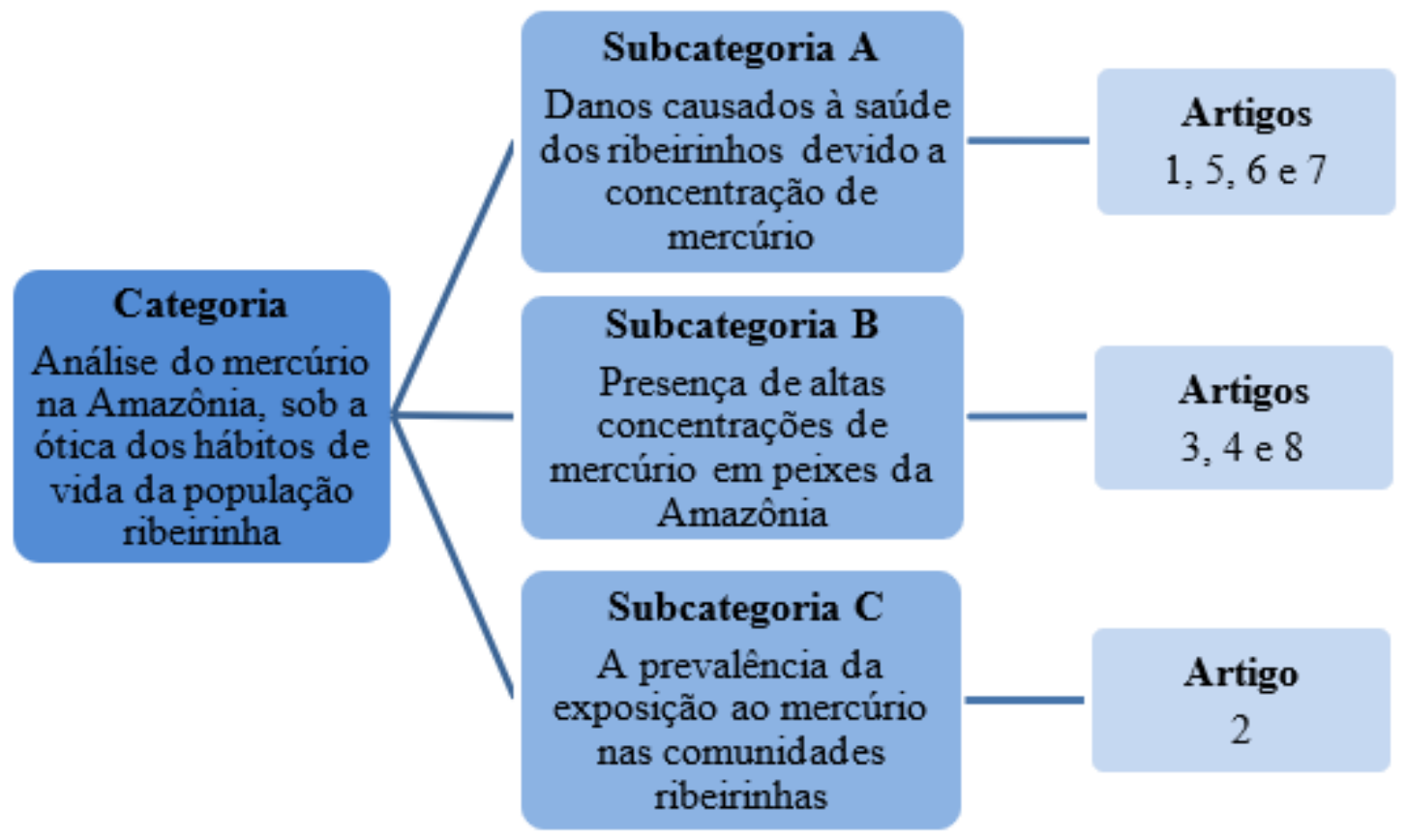

Fonte: Gomes BLC, et al., 2021. 
Quadro 1 - Síntese das principais informações encontradas nos artigos selecionados.

\begin{tabular}{|c|c|c|c|c|c|}
\hline $\mathbf{N}^{\circ}$ & Título do Artigo & $\begin{array}{l}\text { Autor Principal } \\
\text { e Ano da } \\
\text { publicação }\end{array}$ & Objetivos & $\begin{array}{l}\text { Periódico/ } \\
\text { Fonte }\end{array}$ & Resultados \\
\hline 1 & $\begin{array}{l}\text { Manifestações } \\
\text { emocionais e motoras } \\
\text { de ribeirinhos expostos } \\
\text { ao mercúrio na } \\
\text { Amazônia }\end{array}$ & $\begin{array}{l}\text { Costa Junior } \\
\text { JMF } \\
(2018)\end{array}$ & $\begin{array}{l}\text { Analisar as manifestações } \\
\text { emocionais e motoras de } \\
\text { ribeirinhos expostos pela dieta nos } \\
\text { municípios de Itaituba e Acará, } \\
\text { ambos no Pará. }\end{array}$ & $\begin{array}{l}\text { Revista Brasileira } \\
\text { de Epidemiologia }\end{array}$ & $\begin{array}{l}\text { Maiores manifestações de distúrbios motores e } \\
\text { emocionais em ribeirinhos da região de } \\
\text { Itaituba relacionados a maior concentração de } \\
\mathrm{Hg} \text {, se comparado aos ribeirinhos da região do } \\
\text { Acará. }\end{array}$ \\
\hline 2 & $\begin{array}{l}\text { Prevalência e fatores } \\
\text { associados à exposição } \\
\text { ao mercúrio em } \\
\text { comunidades ribeirinhas } \\
\text { na Amazônia Ocidental } \\
\text { Brasileira }\end{array}$ & $\begin{array}{l}\text { Mendes VA } \\
(2020)\end{array}$ & $\begin{array}{c}\text { Verificar a prevalência da } \\
\text { exposição ao mercúrio e identificar } \\
\text { seus possíveis fatores associados } \\
\text { em duas comunidades ribeirinhas } \\
\text { da bacia do Rio Madeira da } \\
\text { Amazônia Ocidental Brasileira. }\end{array}$ & $\begin{array}{c}\text { Revista Brasileira } \\
\text { de } \\
\text { Enfermagem }\end{array}$ & $\begin{array}{l}\text { A prevalência de exposição ao mercúrio em } \\
\text { crianças e adolescentes ribeirinhos foi } \\
\text { considerada alta, com associação ao consumo } \\
\text { de peixe, adolescência, ter parasita e baixa } \\
\text { estatura. }\end{array}$ \\
\hline 3 & $\begin{array}{l}\text { Mercury in fish and } \\
\text { sediment of Purus River, } \\
\text { Acre State, Amazon }\end{array}$ & $\begin{array}{l}\text { Castro NSS } \\
(2016)\end{array}$ & $\begin{array}{l}\text { Quantificar o teor de mercúrio }(\mathrm{Hg}) \\
\text { em sedimentos e em peixes } \\
\text { coletados ao longo do rio Purus, no } \\
\text { Estado do Acre, Região } \\
\text { Amazônica, a fim de identificar se } \\
\text { essas amostras conferem uma via } \\
\text { potencial de exposição do Hg para } \\
\text { a população de Manoel Urbano } \\
\text { (uma comunidade ribeirinha) }\end{array}$ & $\begin{array}{c}\text { Caderno Saúde } \\
\text { Coletiva }\end{array}$ & $\begin{array}{l}\text { A elevada taxa de mercúrio }(\mathrm{Hg}) \text { em peixes } \\
\text { com maior posição trófica é caracterizada por } \\
\text { acumular em peixes carnívoros, assim a } \\
\text { exposição da população da cidade de Manuel } \\
\text { Urbano (Ac) ao Hg aumenta. Sendo o rio } \\
\text { Puros internacional onde traz o Hg advindo de } \\
\text { diversos países localizados em seu curso. }\end{array}$ \\
\hline 4 & $\begin{array}{l}\text { Teores de mercúrio em } \\
\text { cabelo e consumo de } \\
\text { pescado de } \\
\text { comunidades ribeirinhas } \\
\text { na Amazônia brasileira, } \\
\text { região do Tapajós }\end{array}$ & $\begin{array}{l}\text { Costa Junior } \\
\text { JMF } \\
(2018)\end{array}$ & $\begin{array}{c}\text { Avaliar os níveis de exposição na } \\
\text { região do Tapajós, identificando } \\
\text { também a frequência de ingestão } \\
\text { de pescado, propondo testar a } \\
\text { hipótese de que nos anos } \\
2013 / 2014 \text { houve diferença na } \\
\text { concentração de mercúrio e na } \\
\text { frequência de ingestão de pescado } \\
\text { nas comunidades ribeirinhas do } \\
\text { município de Itaituba/PA. }\end{array}$ & $\begin{array}{l}\text { Ciência \& Saúde } \\
\text { Coletiva. }\end{array}$ & $\begin{array}{l}\text { A concentração média de mercúrio total (Hgt), } \\
\text { além do consumo do pescado de comunidades } \\
\text { ribeirinhas no Tapajós, ao relacionar os níveis } \\
\text { de Hgt a ingestão do pescado, identificaram o } \\
\text { aumento no consumo do pescado e na } \\
\text { concentração do HgT,de } 7,83 \mathrm{mg} / \mathrm{g} \text { para } 11,19 \\
\text { mg/g no consumo, porém não houve aumento } \\
\text { expressivo de HgT. }\end{array}$ \\
\hline
\end{tabular}




\begin{tabular}{|c|c|c|c|c|c|}
\hline $\mathbf{N}^{\circ}$ & Título do Artigo & $\begin{array}{l}\text { Autor Principal } \\
\text { e Ano da } \\
\text { publicação }\end{array}$ & Objetivos & $\begin{array}{l}\text { Periódico/ } \\
\text { Fonte }\end{array}$ & Resultados \\
\hline 5 & $\begin{array}{l}\text { Zumbido em uma } \\
\text { população ribeirinha } \\
\text { exposta ao } \\
\text { metilmercúrio }\end{array}$ & $\begin{array}{l}\text { Cardoso NA } \\
(2014)\end{array}$ & $\begin{array}{c}\text { Estudar a prevalência de zumbido, } \\
\text { verificando se há associação entre } \\
\text { a queixa desse sintoma e o teor de } \\
\text { mercúrio e mensurar seu impacto } \\
\text { na qualidade de vida. }\end{array}$ & $\begin{array}{l}\text { Academia Brasileira } \\
\text { de Audiologia }\end{array}$ & $\begin{array}{l}\text { A comunidade do Lago do Puruzinho } \\
\text { apresentou alta prevalência de queixa de } \\
\text { zumbido. Entretanto, não foi verificada } \\
\text { associação entre a queixa de zumbido e os } \\
\text { teores de mercúrio pesquisados. Mensurando } \\
\text { o impacto do zumbido na qualidade de vida, a } \\
\text { maior parte dos ribeirinhos apresentou } \\
\text { handicap de grau leve. }\end{array}$ \\
\hline 6 & $\begin{array}{c}\text { Assessment of mercury } \\
\text { contamination in Brycon } \\
\text { falcatus (Characiformes: } \\
\text { Bryconidae) and human } \\
\text { health risk by } \\
\text { consumption of this fish } \\
\text { from the Teles Pires } \\
\text { River, Southern } \\
\text { Amazonia } \\
\end{array}$ & $\begin{array}{l}\text { Matos LS } \\
(2018)\end{array}$ & $\begin{array}{l}\text { O objetivo deste estudo foi analisar } \\
\text { a presença e concentração de } \\
\text { mercúrio total (THg) no músculo, } \\
\text { fígado e brânquias de B. falcatus, e } \\
\text { calcular o risco à saúde humana } \\
\text { da contaminação por THg pela } \\
\text { ingestão do peixe. }\end{array}$ & $\begin{array}{l}\text { Ictiologia } \\
\text { Neotropical }\end{array}$ & $\begin{array}{l}\text { As concentrações de THg no músculo de B. } \\
\text { falcatus estão abaixo do limite recomendado } \\
\text { pela Organização Mundial de Saúde para } \\
\text { pessoas que consomem até } 250 \mathrm{~g} \text { de peixe } \\
\text { por semana. O risco de efeitos deletérios à } \\
\text { saúde humana pode existir se houver um } \\
\text { consumo maior de B. falcatus como } 340 \mathrm{~g} / \text { dia, } \\
\text { que é a média de consumo de pescado por } \\
\text { indígenas e ribeirinhos. }\end{array}$ \\
\hline 7 & $\begin{array}{l}\text { Manifestações } \\
\text { neurológicas em } \\
\text { ribeirinhos de áreas } \\
\text { expostas ao mercúrio na } \\
\text { Amazônia brasileira }\end{array}$ & $\begin{array}{l}\text { Khoury EDT } \\
\text { (2013) }\end{array}$ & $\begin{array}{c}\text { Expor os estudos de caso que } \\
\text { ilustram a perspectiva das } \\
\text { populações amazônicas que } \\
\text { envolvam o aspecto de } \\
\text { bioantropologia no cenário } \\
\text { brasileiro, especialmente na } \\
\text { Amazônia. }\end{array}$ & $\begin{array}{c}\text { Caderno de Saúde } \\
\text { Pública }\end{array}$ & $\begin{array}{c}\text { Relata que a região de São Luiz do Tapajós é } \\
\text { a com maior concentração de mercúrio, sendo } \\
\text { evidenciada nos cabelos dos moradores desse } \\
\text { local, já as manifestações clínico-neurológicas, } \\
\text { nem sempre são maiores nessa região da } \\
\text { avaliação ou exames propostos }\end{array}$ \\
\hline 8 & $\begin{array}{l}\text { Bioaccumulation of } \\
\text { methylmercury in fish } \\
\text { tissue from the } \\
\text { Roosevelt } \\
\text { River, Southwestern } \\
\text { Amazon basin }\end{array}$ & $\begin{array}{c}\text { Anjos MR } \\
(2015)\end{array}$ & $\begin{array}{l}\text { Analisar a concentração de } \\
\text { metilmercúrio (MeHg) em tecidos } \\
\text { de peixes do rio Roosevelt. }\end{array}$ & $\begin{array}{c}\text { Revista Ambiente \& } \\
\text { Água }\end{array}$ & $\begin{array}{l}\text { A concentração de MeHg variou por hábitos } \\
\text { alimentares. Este estudo demonstrou } \\
\text { bioacumulação de MeHg em tecidos de } \\
\text { peixes, como segue: carnívoros > detritívoros } \\
\text { > frugívoros. Baixas correlações entre peso ou } \\
\text { cumprimento de peixe e MeHg foram } \\
\text { encontradas. }\end{array}$ \\
\hline
\end{tabular}

Fonte: Gomes BLC, et al., 2021. 
Após a análise de identificação dos domínios textuais e interpretação dos significados, buscou-se nomear seus respectivos sentidos em classes descritas a seguir: 1) Aspectos sociais e alimentares da população ribeirinha 2) Influência dos garimpos na concentração mercurial nos peixes 3) Grau de contaminação mercurial em peixes na bacia da Amazônia 4) Relação de contato da comunidade ribeirinha com o potencial tóxico do mercúrio 5) Associação entre as altas concentrações de exposição ao mercúrio e as manifestações clínicas.

\section{DISCUSSÃO}

\section{Classe 1: Aspectos sociais e alimentares da população ribeirinha}

A ocupação da região amazônica iniciou-se durante o século XIX, no decorrer do primeiro ciclo da borracha, composta majoritariamente por nordestinos, posteriormente, iniciou-se o processo de formação da população. Os habitantes da região amazônica são originários da mistura de negros, brancos e indígenas, etnias as quais compõem os grupos sociais da população nessa região. As comunidades ribeirinhas são constituídas por agricultores, seringueiros, pescadores e artesãos, que produzem por exemplo a peneira e a olaria na fabricação de telhas de barro e vasos de cerâmicas. Desse modo, os rios tornam-se o principal meio de renda, socialização e práticas culturais dessas comunidades (CORRÊA AAS, et al., 2019).

A atividade pesqueira na Amazônia, é uma das principais práticas utilizadas para a subsistência, a qual fornece a principal fonte nutritiva proteica para as populações ribeirinhas que vivem próximo às margens dos rios, devido sua grande diversidade de espécies de peixes encontradas na região (SOARES JF, et al., 2016). Diante disso, é evidenciado que nas comunidades ribeirinhas que consomem regularmente peixes na alimentação há uma maior exposição ao nível de mercúrio (COSTA JÚNIOR JMF, et al., 2018).

A população ribeirinha é composta pelos pescadores, extrativistas, além da comunidade que vive nas redondezas dos rios, os quais são utilizados para o transporte e como fonte de alimentação devido ao pescado. Essa população caracteriza-se por ter como principal atividade econômica a agricultura de subsistência e a pesca para garantir a alimentação da comunidade, haja vista a abundância dos recursos naturais encontrados na região amazônica. Nesse contexto, essa população tem como sustento os alimentos advindos dessas atividades, sendo assim, a sua alimentação consiste no pescado e na farinha de mandioca produzida nas próprias comunidades, tornando esses alimentos as principais fontes nutricionais dessa população (MERCADO DS, et al., 2015).

\section{Classe 2: Influência dos garimpos na concentração mercurial nos peixes}

O elemento químico mercúrio $(\mathrm{Hg})$ foi utilizado ao longo dos anos, mundialmente, devido às suas características antropológicas dependentes da pecuária e da ancestralidade, sendo assim, importante na alimentação, cultura e sociedade. $\mathrm{O} \mathrm{Hg}$ é considerado um dos metais pesados de maior toxicidade no meio é caracterizado por sua capacidade de bioacumulação nos organismos e biomagnificação por meio da cadeia alimentar, esse fator pode ser explicado pela localização geográfica, visto que o fluxo de $\mathrm{Hg}$ na Amazônia, tem sido afetado historicamente pelo processo de extração do ouro (CASTRO NSS, et al., 2016).

A descoberta e a corrida em busca do ouro deram início à história da garimpagem amazônica e consequentemente aumentaram a liberação do mercúrio, haja vista que tal componente era muito utilizado no processo de mineração para a separação de partículas finas de ouro por meio de amalgamação, resultando na liberação de quantidades variáveis do mercúrio na forma metálica que contaminam a atmosfera, afetando rios e solos. Em virtude desses procedimentos serem feitos a céu aberto e o descarte realizado na maioria das áreas de garimpos, esse composto tornou-se um dos metais mais tóxicos lançados na natureza por atividades humanas (VEIGA MM, et al., 2002).

Diante desse contexto, as comunidades ribeirinhas como uma população tradicional são submetidas a altos riscos de contaminação, em razão de sua localização geográfica, hábitos alimentares e estilo de vida, haja vista que esse composto tóxico afeta grandes extensões territoriais e sistemas fluviais e, consequentemente, afeta os pescados que representam a alimentação básica para essa comunidade. Assim, 
a poluição ambiental atinge essas comunidades por meio da dieta e exposição da bioacumulação do metilmercúrio pela cadeia alimentar, o qual contamina os peixes e torna-se o principal elemento na via de exposição para esta população (COSTA JÚNIOR JMF, et al., 2018).

\section{Classe 3: Grau de contaminação mercurial em peixes na bacia da Amazônia}

O mercúrio, ao entrar nas águas dos grandes rios amazônicos, sofre alteração na sua forma química, que passa de $\mathrm{Hg}$ inorgânico para orgânico - o metilmercúrio $(\mathrm{MeHg})$. Esse processo é chamado de metilação e ocorre gradativamente. Na Amazônia, o Hg presente no solo é transportado para as bacias dos rios da região e bioacumula-se no tecido muscular dos peixes, de modo que aumenta a concentração de metilmercúrio, conforme a posição mais elevada na cadeia trófica. Isso torna a ingestão de peixes o principal meio de contaminação humana para a forma química mais tóxica do mercúrio (MeHg) (MENDES VA, et al., 2020).

Os níveis de metilmercúrio foram encontrados em altas concentrações nas espécies de peixes com hábitos alimentares carnívoros e piscívoros, além de demonstrar que indivíduos que consomem o referido alimento mais de duas vezes por semana estão mais expostos ao elemento tóxico (MENDES VA, et al., 2020). Por isso, entender o consumo de pescado por essas populações tradicionais é de grande relevância para 0 entendimento da contaminação por mercúrio e seus possíveis efeitos adversos à saúde.

Segundo a Resolução $n^{\circ} 42$, de 29 de agosto de 2013, que dispõe sobre o Regulamento Técnico MERCOSUL sobre Limites Máximos de Contaminantes Inorgânicos em Alimentos, a quantidade máxima de mercúrio em peixes é de: $0,5 \mathrm{mg} / \mathrm{Kg}$ em peixes não predadores ou carnívoros e $1,0 \mathrm{mg} / \mathrm{Kg}$ em peixes predadores (BRASIL, 2013). Diante desse contexto, as obras literárias, que abordam tal problemática de concentração de mercúrio em peixes, evidenciaram dados alarmantes sobre as concentrações médias deste contaminante nos tecidos dos peixes da Amazônia.

Apenas espécies de peixes carnívoras exibiram concentrações de MeHg acima do limite determinado pela Organização Mundial da Saúde (OMS) em alimentos para consumo humano. Os resultados destacam os pescados carnívoros como bons indicadores de contaminação por $\mathrm{MeHg}$ e expressam a ocorrência de bioacumulação do $\mathrm{MeHg}$ em teias alimentares de peixes no sudoeste da Bacia Amazônica. Ademais, os estudos indicaram o rio Madeira e seus afluentes como a principal via de exportação de $\mathrm{Hg}$ para seus sistemas aquáticos associados a fatores ambientais e antrópicos (ANJOS MR, et al., 2016).

O conteúdo de THg no músculo variou de 0,004 a 5,384 $\mu \mathrm{g} \cdot \mathrm{g}-1$. As espécies carnívoras apresentaram o maior nível de $\mathrm{Hg}$ (média de $0,927 \mu \mathrm{g} . \mathrm{g}-1$ ), seguida de piscívora (média de $0,873 \mu \mathrm{g} . \mathrm{g}-1$ ). As espécies Calophysus macropterus, Hydrolycus scomberoides, Rhaphiodon vulpinus, Cetopsis coecutiens, Sorubim lima, Pinirampus pirinampu, Plagioscion squamosissimus e Hypophthalmus edentatus apresentaram níveis médios de THg superiores ao limite recomendado para consumo humano de peixes estabelecido pela OMS (0,5 $\mu \mathrm{g} . \mathrm{g}-1)$, representando $44 \%$ das espécies coletadas (CASTRO NSS, et al., 2016).

Desse modo, vale salientar que as condições de bioacumulação nos peixes refletem a realidade local das águas e de fenômenos nos solos tanto naturais quanto decorrente de ações antrópicas, tornando a biota aquática em possíveis vetores de impactos ambientais os quais podem influenciar a saúde humana. Um exemplo bem claro desse cenário é que a concentração de THg no fígado e tecido muscular de $B$. falcatus foi maior do que a encontrada no tecido branquial. As brânquias, por sua vez, estão em contato direto com o meio aquático e, por serem responsáveis pelo processo de trocas gasosas entre o organismo e o meio, são extremamente irrigadas pelo sangue. Assim, os níveis de concentração neste órgão refletem os do meio externo (água do rio) e do sangue do organismo (MATOS LS, et al., 2018).

Mediante os estudos levantados, infere-se que existem vários fatores relacionados com a promoção do acúmulo de $\mathrm{Hg}$ nas espécies de peixes em regiões de proximidade de comunidade ribeirinhas, quantidades as quais se mantém em níveis elevados ou excedem a quantidade máxima estipulada pela OMS, ocasionando um risco inerente ao desenvolvimento de quadros clínicos decorrentes da ingestão dos peixes contaminados por mercúrio na Amazônia. Tal perspectiva de graus numéricos de concentração de mercúrio quando relacionada a um âmbito cultural alimentício da vida dos ribeirinhos expõe uma realidade de vulnerabilidade inerente a essa população. 


\section{Classe 4: Relação de contato da comunidade ribeirinha com o potencial tóxico do mercúrio}

Na Amazônia o contato em grande escala com o mercúrio $(\mathrm{Hg})$ pode ser datado a partir da década de 80 , devido a atividade de garimpo que se destacou na região, assim como a própria ocupação desordenada, práticas de desmatamentos e queimadas para a retirada. Ademais, sendo o consumo de pescado a principal fonte de alimentação dos ribeirinhos, e essas atividades promovem a entrada do $\mathrm{Hg}$ nos rios, isso torna a ingestão de peixes o principal meio de contaminação humana para a forma química mais tóxica do mercúrio (MENDES VA, et al., 2020).

Como supracitado, o ser humano tende a ser o mais atingido pelo composto de metilmercúrio, por estar em último lugar na cadeia trófica, devido às características lipofílicas do composto que tendem a bioacumular e biomagnificar, assim, o MeHg é absorvido quase que totalmente pelo trato gastrointestinal, e sua toxicologia é capaz de ultrapassar tanto barreiras hematoencefálicas e placentárias, quanto atingir o sistema nervoso central (MENDES VA, et al., 2020).

A relação entre o teor tóxico do mercúrio com a comunidade ribeirinha vai muito além das práticas próximas do garimpo. Em um estudo publicado na revista "Ecotoxicology and Environmental Safety", ao analisar o histórico da região de proximidade das comunidades ribeirinhas de Tucuruí, os pesquisadores constataram a existência de vários pontos de mineração e nenhum deles estava ligado à extração do ouro. A partir disso, sugeriram que a principal fonte de contaminação seria decorrente do efeito indireto provocado pelas barragens de Tucuruí, ou seja, a construção dessas barragens cria ecossistemas fechados que periodicamente são inundados (ANDRADE RO, 2018).

Assim, todos os anos, na época chuvosa, quando o rio transborda e invade a floresta, suas águas ricas em matéria orgânica em decomposição misturam-se a grande quantidade de matéria orgânica jovem. Com o tempo, sob a ação da luz solar, estes compostos produzem peróxido de hidrogênio (água oxigenada), que ajuda a liberar o mercúrio inorgânico estocado no solo. Em seguida, bactérias anaeróbicas convertem a substância em metilmercúrio, que entra na cadeia alimentar aquática (ANDRADE RO, 2018).

A exposição dos ribeirinhos ao $\mathrm{Hg}$ é alarmante, haja vista os danos à saúde que esse contato traz a essa população, devido ao seu alto poder bioacumulativo e ao nível de teor tóxico, sendo prejudicial à saúde, principalmente a mulheres no período gestacional. O contato durante um prolongado tempo ao metilmercúrio, acarreta em vários riscos à saúde visto que pode causar danos no sistema auditivo, disfunções cerebrais, distúrbio visual entre outras degenerações danosas à saúde. Logo, o alto nível de exposição aliado a motivos de liberação do metilmercúrio no ambiente, favorecem a mudanças na saúde dos ribeirinhos (CARDOSO NA, et al., 2014). Diante disso, expõem-se por meio das literaturas que a vulnerabilidade de exposição da comunidade ribeirinha é um risco para o desenvolvimento de quadros clínicos relacionados à bioacumulação do mercúrio.

\section{Classe 5: Associação entre as altas concentrações de exposição ao mercúrio e as manifestações clínicas}

Os estudos demonstraram a grande exposição das comunidades ribeirinhas ao $\mathrm{Hg}$ pela concentração do composto em amostras de cabelo que é considerada um dos melhores bioindicadores da ingestão de alimentos contaminados. Tal contaminação ocorre por meio dos compostos solúveis que são absorvidos pelas mucosas e fixam-se no sangue às proteínas (albumina) e aos glóbulos vermelhos, em seguida são distribuídos para vários sistemas orgânicos, além de causar danos por transpor a barreira placentária e atingir fetos em desenvolvimento em mulheres grávidas, devido sua grande lipossolubilidade e ausência de carga elétrica. Nesse sentido, é importante o monitoramento das concentrações e a investigação de todos os sinais clínicos, haja vista que a exposição ao $\mathrm{Hg}$ pode afetar vários outros sistemas e a saúde da população amazônica (INTOXICAÇÃO POR MERCÚRIO: CAUSAS, SINAIS E SINTOMAS, DIAGNÓSTICO, TRATAMENTO, PREVENÇÃO, 2013).

A toxicidade do metilmercúrio afeta o sistema nervoso central e se acumula no organismo em altas concentrações no cérebro, fígado e rins ocasionando diversas doenças que afetam a saúde física e psíquica dessa população. A exposição aguda ao $\mathrm{MeHg}$ pode provocar uma intoxicação crônica que fomenta diversas 
patologias como a diminuição da coordenação motora com alteração da fala e do andar, parestesia, tremores, neurastenia, falta de equilíbrio, fadiga, sensação de fraqueza, dificuldade de concentração, diminuição do campo visual e a perda auditiva. Além disso, os efeitos tóxicos podem resultar em coma e até morte, tornando esse composto um grande fator de risco para essas populações tradicionais (CARDOSO NA, et al., 2014).

Dessa maneira, ao analisar três comunidades ribeirinhas na Amazônia, sendo elas de tais localidades: São Luiz do Tapajós, Barreiras e Furo do Maracujá, observou-se a incidência de manifestações clínicas neurológicas, variando as frequências conforme a comunidade analisada. A exemplo daquelas estão: fraqueza nas pernas, alteração da marcha, alteração de nervos cranianos, diminuição da sensibilidade tátil e dolorosa e adormecimento das mãos (KHOURY EDT, et al., 2013). Ainda, segundo dados de outro estudo, ao analisar queixas motoras e emocionais nos ribeirinhos associadas às concentrações de $\mathrm{Hg}$, a frequência foi maior em Barreiras e São Luiz do Tapajós, ambas na região de Itaituba (COSTA JÚNIOR JMF, et al., 2018).

\section{CONSIDERAÇÕES FINAIS}

Logo, o presente artigo possibilitou analisar o parâmetro de todas as vertentes que as literaturas abordam sobre a exposição, o adoecimento e a ingestão do mercúrio pela população ribeirinha na Amazônia. Constatou-se, que aquela está altamente exposta ao mercúrio, devido suas relações diretas e indiretas com o meio, que são fatores de risco de contaminação, como por exemplo, seus hábitos alimentares (elevado consumo de peixes); e o histórico de construção de hidrelétricas e garimpos (uso excessivo do metal). Com isso, essas comunidades estão vulneráveis a sofrerem manifestações emocionais e motoras, além de quadros de alterações fisiológicas e doenças neurológicas.

\section{REFERÊNCIAS}

1. ANDRADE RO. Áreas da Amazônia alagadas por hidrelétricas podem aumentar níveis de mercúrio em peixes consumidos por moradores locais. Revista Pesquisa FAPESP, 2018; 19(265): 61-63.

2. ANJOS MR, et al. Bioacumulação de metilmercúrio em tecido de peixe do Rio Roosevelt, sudoeste da bacia amazônica. Revista Ambiente e Água, 2016; 11(3): 508-518.

3. BRASIL. Política Nacional de Saúde Integral das Populações do Campo e da Floresta. 2013. Disponível em: https://bvsms.saude.gov.br/bvs/publicacoes/politica_nacional_saude_populacoes_campo.pdf. Acessado em: 23 de fevereiro de 2021

4. BRASIL. Regulamento Técnico MERCOSUL sobre Limites Máximos de Contaminantes Inorgânicos em Alimentos. $\begin{array}{lllll}\text { Biblioteca } & \text { Virtual } & \text { Saúde. } & 2013 . & \text { Disponível }\end{array}$ http://bvsms.saude.gov.br/bvs/saudelegis/anvisa/2013/rdc0042_29_08_2013.html. Acessado em: 14 de fevereiro de 2021.

5. CARDOSO NA, et al. Zumbido em uma população ribeirinha exposta ao metilmercúrio. Academia Brasileira de Audiologia, 2014; 19(1): 40-44.

6. CARTA P, et al. Anormalidades neurocomportamentais subclínicas associadas ao baixo nível de exposição ao mercúrio por meio do consumo de peixe. Revista NeuroToxicology, 2003; 24(4-5): 617-623.

7. CASTRO NSS, et al. Mercúrio em peixe e em sedimento do Rio Purus, Estado do Acre, Amazônia. Revista Cadernos Saúde Coletiva, 2016; 24(3): 294-300.

8. CORREAA AAS, et al. No Linear da Tradição e Modernidade: a Cultura Alimentar caipira, caiçara e das Populações Ribeirinhas Paraenses. Revista Comportamento, Cultura e Sociedade, 2019; 6(2): 14-29.

9. COSTA JÚNIOR JMF, et al. Manifestações emocionais e motoras de ribeirinhos expostos ao mercúrio na Amazônia. Revista Brasileira de Epidemiologia, 2017; 20(2): 212-224

10. COSTA JÚNIOR JMF, et al. Teores de mercúrio em cabelo e consumo de pescado de comunidades ribeirinhas na Amazônia brasileira, região do Tapajós. Revista Ciência \& Saúde Coletiva, 2018; 23(3): 805-812.

11. FRANCO EC, et al. Promoção da saúde da população ribeirinha da região amazônica: relato de experiência. Revista CEFAC, 2015; 17(5): 1521-1530.

12. INTOXICAÇÃO POR MERCÚRIO: CAUSAS, SINAIS E SINTOMAS, DIAGNÓSTICO, TRATAMENTO, PREVENÇÃO. 2013. In: AbcMed. Disponível em: https://www.abc.med.br/p/sinais.-sintomas-edoencas/351414/intoxicacao+por+mercurio+causas+sinais+e+sintomas+diagnostico+tratamento+prevencao.htm. Acesso em: 16 fev. 2021.

13. KHOURY EDT, et al. Manifestações neurológicas em ribeirinhos de áreas expostas ao mercúrio na Amazônia brasileira. Cadernos de Saúde Pública, 2013; 29(11): 2307-2318.

14. LIRA, TM, CHAVES MPSR. Comunidades ribeirinhas na Amazônia: organização sociocultural e política. Revista Interações (Campo Grande), 2016; 17(1): 66-76. 
15. MATOS LS, et al. Avaliação da contaminação por mercúrio em Brycon falcatus (Characiformes: Bryconidae) e do risco à saúde humana pelo consumo deste peixe do rio Teles Pires, sul da Amazônia. Revista Neotropical lchthyology, 2018; 16(1): e160106.

16. MENDES VA, et al. Prevalência e fatores associados à exposição ao mercúrio em comunidades ribeirinhas na Amazônia Ocidental Brasileira. Revista Brasileira de Enfermagem, 2020; 73(supl. 5): e20200100.

17. MERCADO DS, et al. Hábitos alimentares de ribeirinhos da Amazônia e contribuições das enchentes no agravo ao quadro de insegurança alimentar. Revista Saber Científico, 2015; 4(1): 14-18.

18. PIMENTEL DR, et al. Avaliação dos Níveis de Mercúrio $(\mathrm{Hg})$ total em peixes de igarapés da bacia do Rio Mamuru, Pará, Brasil. Revista Saúde e Meio Ambiente, 2019; 9(3): 34-46.

19. SOARES JLF, et al. Bioacumulação de mercúrio total (HgT) e hábitos alimentares de peixes da bacia do Rio Negro, Amazônia, Brasil. Revista Biota Amazônia (Biote Amazonie, Biota Amazonia, Amazonian Biota), 2016; 6(1): $102-106$.

20. SOUZA JR, BARBOSA AC. Contaminação por mercúrio e o caso da Amazônia. Revista Química Nova na Escola, 2000; 12(1): 03-07.

21. VEIGA MM, et al. Extração de ouro: princípios, tecnologia e meio ambiente. Rio de Janeiro: CETEM/MCT, 2002; $267 p$. 